OPEN ACCESS

Edited by:

Sivakumar $S$,

Pusan National University,

South Korea

Reviewed by:

Xueqing Wu,

Sir Run Run Shaw Hospital, China

Yong Shi,

Karolinska Institutet (KI), Sweden

Xiang-Dang Du,

Henan Agricultural University, China

*Correspondence:

Qianxue Li

lqxue@hotmail.com

Dacheng Wang

wangdc@jlu.edu.cn

${ }^{\dagger}$ These authors have contributed equally to this work

Specialty section:

This article was submitted to Antimicrobials, Resistance

and Chemotherapy,

a section of the journal

Frontiers in Microbiology

Received: 28 March 2021

Accepted: 14 June 2021

Published: 06 July 2021

Citation:

Wang L, Wang G, Qu H, Wang K,

Jing S, Guan S, Su L, Li Q and

Wang D (2021) Taxifolin, an Inhibitor

of Sortase A, Interferes With

the Adhesion of Methicillin-Resistant

Staphylococcal aureus.

Front. Microbiol. 12:686864.

doi: 10.3389/fmicb.2021.686864

\section{Taxifolin, an Inhibitor of Sortase A, Interferes With the Adhesion of Methicillin-Resistant Staphylococcal aureus}

\author{
Li Wang ${ }^{1 \dagger}$, Guangming Wang ${ }^{2 \dagger}$, Han $\mathrm{Qu}^{3}$, Kai Wang ${ }^{3}$, Shisong Jing ${ }^{1}$, Shuhan Guan', \\ Liyan Su${ }^{4}$, Qianxue $\mathrm{Li}^{3 *}$ and Dacheng Wang ${ }^{* *}$
}

${ }^{1}$ College of Animal Science, Jilin University, Changchun, China, ${ }^{2}$ Department of Neurosurgery, The First Hospital of Jilin University, Changchun, China, ${ }^{3}$ Changchun Veterinary Research Institute, Chinese Academy of Agricultural Sciences, Changchun, China, ${ }^{4}$ College of Veterinary Medicine, Jilin University, Changchun, China

The evolution and spread of methicillin-resistant Staphylococcus aureus (MRSA) poses a significant hidden risk to human public health. The majority of antibiotics used clinically have become mostly ineffective, and so the development of novel anti-infection strategies is urgently required. Since Staphylococcus aureus (S. aureus) cysteine transpeptidase sortase A (SrtA) mediates the surface-anchoring of proteins to its surface, compounds that inhibit SrtA are considered potential antivirulence treatments. Herein, we report on the efficacy of the potent SrtA inhibitor taxifolin (Tax), a flavonoid compound isolated from Chinese herbs. It was able to reversibly block the activity of SrtA with an $\mathrm{IC}_{50}$ of $24.53 \pm 0.42 \mu \mathrm{M}$. Tax did not display toxicity toward mammalian cells or S. aureus at a concentration of $200 \mu \mathrm{M}$. In addition, Tax attenuated the virulence-related phenotype of SrtA in vitro by decreasing the adherence of $S$. aureus, reducing the formation of a biofilm, and anchoring of $S$. aureus protein $A$ on its cell wall. The mechanism of the SrtA-Tax interaction was determined using a localized surface plasmon resonance assay. Subsequent mechanistic studies confirmed that Asp-170 and Gln-172 were the principal sites on SrtA with which it binds to Tax. Importantly, in vivo experiments demonstrated that Tax protects mice against pneumonia induced by lethal doses of MRSA, significantly improving their survival rate and reducing the number of viable $S$. aureus in the lung tissue. The present study indicates that Tax is a useful pioneer compound for the development of novel agents against $S$. aureus infections.

Keywords: antivirulence, taxifolin, inhibitor, methicillin-resistant Staphylococcus aureus, sortase A, pneumonia

\section{INTRODUCTION}

There is currently major worldwide concern about the continuous emergence of multidrugresistant bacterial pathogens. Staphylococcus aureus (S. aureus) is recognized as an important cause of disease worldwide. It is capable of inducing a variety of serious diseases that endanger human health, from mild skin and soft tissue infection to fatal invasive infections such as septicemia 
and pneumonia, etc. (Goetghebeur et al., 2007; Tong et al., 2015; Lake et al., 2018). In clinics, antibiotics have been considered as the primary defense against $S$. aureus infections over many decades. In the years following their introduction, the therapeutic benefits of such antibiotics were remarkable. However, the considerable selective pressure and improper use of antibiotics have resulted in the emergence, prevalence, and spread of drugresistant strains of bacteria (Liu et al., 2019; Wu et al., 2019). As strains of methicillin-resistant Staphylococcus aureus (MRSA) with little sensitivity to conventional antibiotics have become prevalent (Prestinaci et al., 2015), treatments for MRSA infection have become more challenging for clinicians, who require new strategies to provide effective therapeutic options against complicated S. aureus infections (Kali, 2015; Galar et al., 2019).

Alternative therapies such as the use of antibiotics in combination or with adjuvants, bacteriophages, antimicrobial peptides, nanoparticles (Nisar et al., 2019) and anti-virulence therapy are widely reported (Mandal et al., 2014; Kaur, 2016). Considering that $S$. aureus exploited a vast repertoire of virulence strategies that enable it to infect a host. Therefore, Therefore, exploration of the potential of these virulence factors as drug targets may represent an alternative approach to disrupt bacterial pathogenicity (Vandenesch et al., 2012). SrtA is a membranebound cysteine transpeptidase that plays an essential role in catalyzing the covalent anchoring of surface proteins to the bacterial cell wall (Paterson and Mitchell, 2004). A member of the sortase subfamily, it plays an active role in bacterial adhesion, biofilm formation, and immune escape (Cascioferro et al., 2014). In addition, S. aureus SrtA-anchored surface proteins play major roles in the infection process, with many studies demonstrating that $S$. aureus SrtA mutants do not form abscess lesions or survive when infecting mouse tissue (Mazmanian et al., 2000; Cheng et al., 2009). Specific SrtA inhibitors do not interfere with the growth of bacteria yet weaken bacterial virulence (Suree et al., 2007; Hou et al., 2018). They have the potential to prevent $S$. aureus-induced colonization and invasive diseases while exhibiting a low risk of causing bacterial resistance by blocking SrtA (Hou et al., 2018).

Novel SrtA inhibitors have been identified from libraries of natural or synthetic compounds, or may be specificallyengineered peptidomimetics (Smeltzer, 2016). Of these, there is widespread interest in natural products with diverse structures and biological properties from fungi and plants (Si et al., 2016). In the present study, characterization of the natural compound taxifolin (Tax) is reported. It is extracted from the roots of larch and is an inhibitor of SrtA. It has been widely studied due to its properties as an antioxidant and inhibitor of the synthesis of fat and cholesterol (Angelis et al., 2016; Razak et al., 2018; Ren et al., 2020). In addition, it has been observed that Tax can inhibit SrtA activity without interfering with the growth of bacteria, suggesting that the use of Tax would result in low selective pressure which would avoid the development of resistant strains. In the present study, the inhibitory mechanisms were investigated in detail and the protective effects of Tax in a murine model of MRSA-induced lethal pneumonia was evaluated. In conclusion, the results indicated that Tax represents a potential anti-MRSA drug.

\section{MATERIALS AND METHODS}

\section{Reagents and Materials}

The peptide substrate Abz-LPATG-Dap (Dnp)- $\mathrm{NH}_{2}$ (Abz:orthoaminobenzoic acid; Dnp:2,4-dinitrophenyl) was provided by LifeTein (Beijing, China). Dimethyl sulfoxide (DMSO) was purchased from Beyotime (Shanghai, China). A library containing 420 natural compounds derived from Chinese traditional herbs was purchased from Pufeide Biotech Company (Chengdu, China).

\section{Bacteria and Growth Conditions}

S. aureus USA300 was obtained from the American Type Culture Collection (Manassas, VA). The S. aureus Newman SrtA deletion mutant $(\triangle s r t A)$ and the pET28a-SrtA strain were already used and stored within the laboratory. E. coli BL21 (DE3) was used as a host for protein expression and purchased from the TransGen Biotech (Beijing, China). E. coli and S. aureus were cultured in Luria-Bertani broth (LB, Hopebio, Qingdao, China) and brain heart infusion medium (BHI, Solarbio, Beijing, China), respectively, at $37^{\circ} \mathrm{C}$ with constant shaking.

\section{Expression and Purification of Recombinant SrtA and Its Mutants}

Site-directed mutagenesis for D170A-SrtA and Q172A-SrtA was performed based on plasmid pET28a-SrtA using a multi-site mutagenesis kit (Transgen, Beijing, China) and the desired mutation was verified via DNA sequencing by Sangon Biotech (Shanghai, China). All primers used in the study are presented in Table 1. Subsequently, recombinant SrtA and the SrtA mutant proteins (D170A and Q172A) were expressed and purified in accordance with a previously published procedure (Zhulenkovs et al., 2014). Briefly, bacteria were cultured until an $\mathrm{OD}_{600}$ value of 0.8 was achieved, after which $0.5 \mathrm{mM}$ isopropyl- $\beta$-D-thiogalactopyranoside (IPTG) was added to induce recombination of SrtA at $16^{\circ} \mathrm{C}$ overnight. Because the recombinant protein had $6 \times \mathrm{His}$ tags, it was purified using a nickel-nitrilotriacetic acid (Ni-NTA) purification system. Imidazole $(10 \mathrm{mM})$ was used to wash away excess protein, while $400 \mathrm{mM}$ imidazole was employed to elute the target protein.

\section{Screening of SrtA Inhibitors}

Fluorescence resonant energy transfer (FRET) was used to determine the effect of Tax on SrtA, as described previously (Kruger et al., 2002). Briefly, $4 \mu \mathrm{M}$ purified recombinant SrtA was combined with various concentrations of Tax then added to assay buffer consisting of $50 \mathrm{mM}$ Tris- $\mathrm{HCl}, 5 \mathrm{mM} \mathrm{CaCl}_{2}, 150 \mathrm{mM}$

TABLE 1 | Primers used in this study.

\begin{tabular}{lc}
\hline Primer name & Sequences $\mathbf{( \mathbf { 5 } ^ { \prime } - \mathbf { 3 } ^ { \prime } \mathbf { ) }}$ \\
\hline D170A - srtA-F & GAGTTCTAGCTGAACAAAAAGG \\
D170A -srtA-R & CTACATCTGTAGGCTTAACATC \\
Q172A -srtA-F & CTAGATGAAGCAAAAGGTAAAG \\
Q172A -sitA-R & AACTCCTACATCTGTAGGCTTA
\end{tabular}


$\mathrm{NaCl}$, at pH 7.5, to a final volume of $200 \mu \mathrm{L}$. Following incubation of the mixture at $37^{\circ} \mathrm{C}$ for $1 \mathrm{~h}$, substrate peptide was added to a final concentration of $10 \mu \mathrm{M}$ and incubated for an additional $30 \mathrm{~min}$. Fluorescence intensity was measured at excitation and emission wavelengths of 309 and $420 \mathrm{~nm}$, respectively.

\section{Susceptibility Assay and Growth Curve}

A broth microdilution assay was performed to determine the minimum inhibitory concentration (MIC) of Tax for S. aureus USA300, as described elsewhere (Sader et al., 2013; DelgadoValverde et al., 2017). A growth curve was further evaluated by adding various concentrations of Tax $(0-200 \mu \mathrm{M})$ to a bacterial culture, then incubating until an $\mathrm{OD}_{600}$ of 0.3 had been reached. S. aureus USA300 and $\Delta s r t A$ were used as controls. The $\mathrm{OD}_{600}$ value was recorded for each sample at $1 \mathrm{~h}$ intervals for a total of $24 \mathrm{~h}$. The growth rate between $S$. aureus treated with Tax and S. aureus USA300 was also calculated at each time point.

\section{Eukaryotic Cytotoxicity}

Cytotoxicity was determined using a cell counting kit-8 assay (CCK-8, US EVERBRIGHT, Suzhou, China), as described previously (Xiao et al., 2018). HEK293 or HepG2 cells were seeded in 96-well plates (Corning, United States) at a density of $5 \times 10^{4}$ cells/well, then incubated at $37^{\circ} \mathrm{C}$ in an atmosphere containing $5 \% \mathrm{CO}_{2}$ for $24 \mathrm{~h}$. The culture medium was then exchanged with fresh medium containing different concentrations of Tax $(0-200 \mu \mathrm{M})$ or vehicle and incubated for an additional $24 \mathrm{~h}$. CCK-8 solution $(10 \mu \mathrm{L})$ was carefully added then incubated for $4 \mathrm{~h}$ in an incubator at $37^{\circ} \mathrm{C}$. The $\mathrm{OD}$ value at $450 \mathrm{~nm}$ was measured to calculate cell viability.

\section{Fibrinogen Binding Assay}

Bacterial cultures grown overnight were diluted (1:100) in fresh BHI medium containing different concentrations of Tax then cultured at $37^{\circ} \mathrm{C}$ until an $\mathrm{OD}_{600}$ of 1.0 had been achieved. The $\Delta s r t A$ strain was used as a positive control. Aliquots of bacteria were placed in the wells of a 96-well plate pre-coated with bovine fibrinogen $(20 \mu \mathrm{g} / \mathrm{mL})$. After incubation at $37^{\circ} \mathrm{C}$ for $2 \mathrm{~h}$, the cell suspension in each well was replaced with $100 \mu \mathrm{L}$ of $25 \%$ formaldehyde then incubated for a further $30 \mathrm{~min}$, after which the formaldehyde was discarded. The plates were washed twice with PBS, and then $0.1 \%(\mathrm{w} / \mathrm{v})$ crystal violet was added to stain the cells. Finally, after $20 \mathrm{~min}$, the wells were gently washed with PBS then dried, and the OD value at $570 \mathrm{~nm}$ was measured.

\section{Effects of Tax on Biofilm Formation}

Bacterial cultures grown overnight were diluted 1:100 in $\mathrm{BHI}$ medium supplemented with $3 \% \mathrm{NaCl}$ and $0.5 \%$ glucose. A $200 \mu \mathrm{L}$ aliquot of each diluted culture was added to separate wells of a 96well plate, to which different concentrations of Tax $(25-200 \mu \mathrm{M})$ had been added, then incubated at $37^{\circ} \mathrm{C}$ for $24 \mathrm{~h}$. Subsequently, the culture medium was replaced with crystal violet to stain the biofilm for $15 \mathrm{~min}$. The wells were then washed thoroughly with sterile deionized PBS three times. The crystal violet stain in each well was decolorized with $200 \mu \mathrm{L}$ absolute ethanol and then the $\mathrm{OD}_{595}$ value was recorded using a microplate reader.

\section{Effects of Tax on Mature Biofilms}

S. aureus biofilms were formed for $24 \mathrm{~h}$ at $37^{\circ} \mathrm{C}$ on the surfaces of the wells of a 96-well plate. Following biofilm formation, different Tax concentrations $(25-200 \mu \mathrm{M})$ were added to selected wells and the plates were incubated for $24 \mathrm{~h}$ at $37^{\circ} \mathrm{C}$. The effects of Tax on the mature biofilms were estimated using the crystal violet stain and recorded by a microplate reader.

\section{FITC-IgG Binding Assay for Staphylococcal Protein A (SpA)}

Bacterial cultures grown overnight were diluted 1:100 and cultured in an incubator at $37^{\circ} \mathrm{C}$ with Tax or DMSO to a concentration of $10^{8} \mathrm{CFU} / \mathrm{mL}$. The $\Delta s r t A$ mutant strain was assayed as a positive control. The bacteria were collected and washed three times in PBS. A $50 \mu \mathrm{L}$ aliquot of bacterial culture was mixed with an equal volume of FITC-labeled rabbit antigoat-IgG (1:200, Sigma, United States) then incubated in the dark for $1 \mathrm{~h}$. The bacteria were then washed and suspended in PBS. A multimode microplate reader (Tecan, Spark 20M) was used to measure fluorescence intensity at $535 \mathrm{~nm}$ when illuminated at an excitation wavelength of $485 \mathrm{~nm}$.

\section{Invasion Assay}

A549 human lung carcinoma cells were seeded at a density of $2.5 \times 10^{5}$ per well in 24-well plates and placed in an incubator at $37^{\circ} \mathrm{C}$ in an atmosphere containing $5 \% \mathrm{CO}_{2}$ for $20 \mathrm{~h}$. Cultures of $S$. aureus were mixed with different concentrations of Tax then cultured at $37^{\circ} \mathrm{C}$ until an $\mathrm{OD}_{600}$ of 1.0 was achieved. The A549 cells were resuspended in medium and aliquots of bacterial suspension were added to each well to a total concentration of $2 \times 10^{7 \circ} \mathrm{CFU} / \mathrm{mL}$. After incubation for $2 \mathrm{~h}$, the invasion assay was terminated by incubation with $300 \mu \mathrm{g} / \mathrm{mL}$ gentamicin for $30 \mathrm{~min}$. The cells were then lysed after washing and coated on a BHI agar plate. After incubation at $37^{\circ} \mathrm{C}$ for $12 \mathrm{~h}$, the number of CFUs were counted manually.

\section{Western Blot Analysis}

To evaluate the effect of Tax on SrtA expression, Tax (25-200 $\mu \mathrm{M})$ was added to different bacterial cultures and incubated overnight at $37^{\circ} \mathrm{C}$. Equal quantities of total protein from the bacterial lysates were separated by 12\% SDS-PAGE then transferred to a polyvinylidene fluoride (PVDF) membrane using a transblot semidry system. Non-specific binding to the PVDF membrane was prevented by incubating in $5 \%$ bovine serum albumin (BSA) overnight at $4^{\circ} \mathrm{C}$. The membranes were washed three times with PBST, agitating each time for $5 \mathrm{~min}$, then incubated with rabbit polyclonal antibody (created in the laboratory) against SrtA. Following a further washing in PBST three times, the membranes were incubated with HRPlabeled goat anti-rabbit IgG (Bioworld, China) diluted 1:10,000 in antibody diluent (PBST $+1 \% \mathrm{BSA})$ at $37^{\circ} \mathrm{C}$ for $1 \mathrm{~h} . \Delta s r t A$ or $S$. aureus USA300 without Tax was considered the control group. The cytoplasmic protein ClpP was analyzed as an internal control. Blots were visualized using an enhanced chemiluminescence (ECL) detection system (GE Healthcare, United Kingdom), 
while bands were quantified using ImageQuant TL software (GE Healthcare).

\section{Localized Surface Plasmon Resonance}

The interaction between Tax and SrtA was determined using an OpenSPR localized surface plasmon resonance (LSPR) instrument (Nicoya, Canada) at $25^{\circ} \mathrm{C}$, as described previously (Panneer Selvam et al., 2018; Song et al., 2019). Briefly, SrtA proteins were captured on a $\mathrm{COOH}$ chip using a standard amine coupling system. A $200 \mu \mathrm{L}$ aliquot of blocking buffer was added to rinse the sample ring and to remove any air. After a stable baseline had been achieved, the affinity between Tax and SrtA was measured by injecting $20,40,80,160$, or $320 \mu \mathrm{M}$ Tax. The kinetic parameters of the binding reaction were calculated and visualized using TraceDrawer software (Yang et al., 2011).

\section{Molecular Docking and Dynamic Simulation}

For molecular docking (MD) simulations, Tax (PubChem ID: 439533) was docked onto the SrtA structure of $S$. aureus [Protein Data Bank (PDB) ID: 1T2P] using AutoDock Vina 1.1.2 software, with default parameters (Trott and Olson, 2010). The most appropriate docked pose (conformation) for the TaxSrtA complex obtained using molecular docking was subject to 25 ns molecular dynamic simulations using Amber14 software (Götz et al., 2012). Preparation of the complex and the molecular dynamic simulation were conducted as previously described (Chan et al., 2017; Niu et al., 2019).

\section{Murine Model of Pneumonia}

To investigate the therapeutic capability of Tax to treat acute pneumonia infection caused by $S$. aureus USA300, 6- to 8week-old female C57BL/6J mice were infected intranasally with $2 \times 10^{8} \mathrm{CFU}$ of $S$. aureus USA300, then held upright for $30 \mathrm{~s}$ to ensure each animal inhaled the bacteria into their lungs. Two $h$ post-infection, the mice were subcutaneously injected with Tax $(100 \mathrm{mg} / \mathrm{kg})$. Similarly, mice were challenged with $\Delta s r t A$ and sterile PBS containing 0.5\% DMSO (control group) as controls. To assess survival, the mice were checked every $12 \mathrm{~h}$ for $96 \mathrm{~h}$, and the percentage that had survived was recorded.

For bacterial counts in lung tissue and histopathological examination, mice were infected intranasally with $30 \mu \mathrm{L}\left(1 \times 10^{8}\right.$ CFUs) of S. aureus USA300. Tax (100 mg/kg) was then injected subcutaneously every $12 \mathrm{~h}$ after inoculation. The bacterial load in the lungs was determined after the mice in each group were sacrificed $48 \mathrm{~h}$ post-infection. The left lung from each animal was removed aseptically and processed to count the bacterial CFUs. The right lung of each mouse was aseptically removed and analyzed by conventional hematoxylin and eosin (H\&E) staining using an optical microscope. The ratio of wet to dry lung tissue weight (W/D ratio) was recorded in each case. Wet lung weight was measured 1 min after surface moisture had been removed. Dry lung weight was determined after dehydration at $80^{\circ} \mathrm{C}$. The W/D ratio is used to reveal the degree of tissue edema (Xia et al., 2016).
Acute toxicity of Tax was evaluated in mice in accordance with the guidelines for the study of acute toxicity of chemical drugs in China (H-GPT1-1) (Carmichael, 2014). Briefly, each group of 5 female $\mathrm{BALB} / \mathrm{c}$ mice (6-8 weeks old, weight $18-20 \mathrm{~g}$ ) was administered a single intraperitoneal injection of 200, 100, or $50 \mathrm{mg}$ per kg bodyweight of Tax, respectively. An injection of PBS represented the control group. Symptoms of poisoning or abnormal behavior were monitored, and survival of the mice in each group was recorded after $72 \mathrm{~h}$.

\section{Ethics Approval Statement}

All animal experiments and surgical procedures were carried out in accordance with guidelines approved by the Animal Welfare and Research Ethics Committee of Jilin University.

\section{Statistical Analysis}

The data were expressed as the mean \pm SD for each group in the individual experiments. The experimental data in this study were analyzed using GraphPad Prism 8.0. Statistical significance was accepted as $P$-values $<0.05$.

\section{RESULTS}

\section{Identification of Tax as a Reversible Inhibitor of SrtA}

To identify novel inhibitors of SrtA, an in-house library containing 420 natural compounds was screened, using a FRET assay. The flavonoid Tax was found to display excellent inhibitory properties against $S$. aureus $\mathrm{SrtA}$, with an $\mathrm{IC}_{50}$ value of $24.53 \pm 0.42 \mu \mathrm{M}$ (Figures 1A,B). This suggests that Tax is a relatively strong inhibitor of SrtA, compared with previously reported inhibitory small molecules (Oh et al., 2004; Chenna et al., 2010). To further clarify the interacting way of SrtA and Tax, recombinant SrtA was reacted with Tax at a concentration of 10 -fold $\mathrm{IC}_{50}$. A total of $85.80 \pm 0.67 \%$ of SrtA activity was subsequently recovered, compared with the control group (DMSO) (Figure 1C). These data demonstrated that Tax was a reversible SrtA inhibitor, and bound non-covalently to the active site of SrtA.

\section{Tax Has No Significant Inhibitory Effect on the Proliferation of S. aureus or Animal Cells}

The MIC of Tax against S. aureus USA 300 was $512 \mu \mathrm{g} / \mathrm{mL}$. The results of the growth curve and growth rate showed that Tax had no significant effect on the growth of $S$. aureus, at a concentration of $\mathrm{IC}_{50}(P>0.05$, Figures 2A,B). Safety testing further revealed that Tax displayed no significant cytotoxicity toward HEK293 and HepG2 cells at the concentration $(24.53 \pm 0.42 \mu \mathrm{M})$ required for repression of SrtA (Figure 2C). Taken together, Tax was effective and safe at the concentration required to inhibit SrtA, it was a promising candidate anti-virulence inhibitor and has the potential to be developed into a small molecule drug based on inhibition of SrtA. 

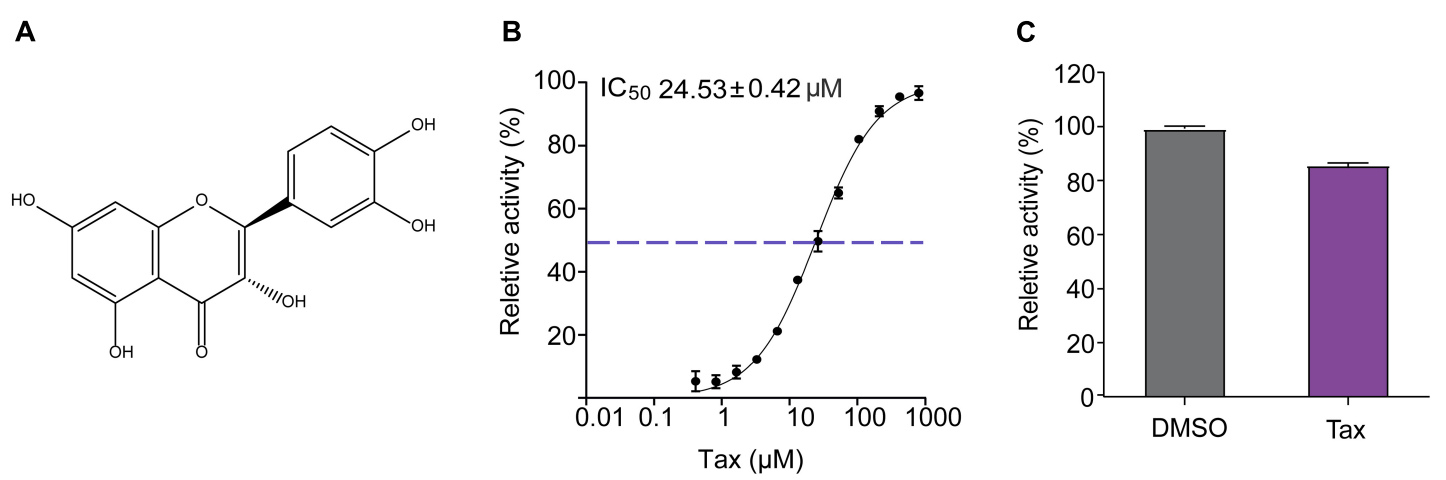

FIGURE 1 | Inhibition of SrtA transpeptidation. (A) Chemical structure of Tax. (B) Tax inhibits SrtA cleavage of a fluorogenic peptide substrate (Abz-LPATG-Dnp-NH 2 ) in a dose-dependent manner in vitro. Each reaction condition was assayed in triplicate from which the $\mathrm{IC}_{50}$ was determined. (C) Recombinant SrtA was treated with $10 \times \mathrm{IC}_{50}$ of Tax and then diluted, after which transpeptidation activity was measured using a FRET assay. Untreated SrtA (Control) represented $100 \%$ activity.
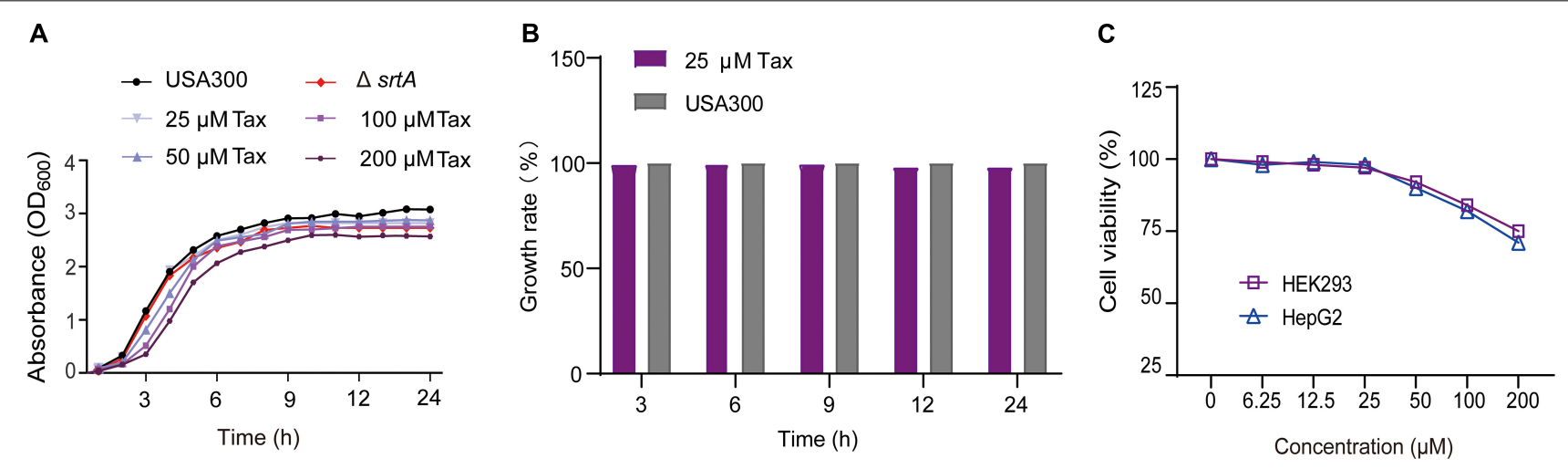

FIGURE 2 | Growth curve and cytotoxicity. (A) Growth curves of S. aureus USA300 and the $\Delta$ srtA group with different concentrations of Tax. (B) Growth rate of S. aureus USA300 and S. aureus treated with Tax (25 $\mu$ M). (C) Percent cell viability of HEK293 (purple) and HepG2 (blue) cells were measured using a CCK-8 assay after incubation with Tax for $24 \mathrm{~h}$.

\section{Tax Represses the Adhesion of S. aureus to Fibrinogen}

To establish whether Tax was able to reduce the adhesion of S. aureus to fibrinogen by inhibiting SrtA, a fibrinogen binding assay was performed. As shown in Figure 3A, Tax inhibited the adhesion of $S$. aureus USA300 to fibrinogen in a dose-dependent manner. Compared with the wild-type (WT) control group, $200 \mu \mathrm{M}$ Tax significantly disrupted the adhesion of bacteria to fibrinogen, with an inhibition rate of $35.09 \pm 0.49 \%(P<0.001)$. This result reveals that Tax reduced the adhesion of bacteria to fibrinogen via inhibition of SrtA.

\section{Tax Reduces Biofilm Formation and Fails to Eradicate Mature Biofilm in S. aureus}

Initial attachment is the first stage of the development of a biofilm. Capture of the multiple surface proteins that are involved is mediated by SrtA (Otto, 2018). Consistent with this, increased expression of SrtA can cause a substantial increase in biofilm biomass in certain staphylococcal strains (Maresso et al., 2007). It can be inferred that Tax can reduce the formation of biofilms. As expected, Tax clearly inhibited biofilm biomass in a concentration-dependent manner. There was an inhibitory effect on biofilm biomass due to the coculture of S. aureus with $200 \mu \mathrm{M}$ Tax, at $29.91 \pm 0.51 \%$ of the mass of the untreated control. Biofilm formation by the $\Delta s r t A$ group was $18.5 \pm 1.02 \%$, indicating that Tax reduces the formation of $S$. aureus biofilms via repression of SrtA activity (Figure 3B). Subsequently, we further evaluated the effects of Tax on mature biofilms, the results showed that different concentrations of Tax $(25-200 \mu \mathrm{M})$ had no effect on mature biofilms (Figure 3C).

\section{Tax Suppresses the Invasion of S. aureus Into A549 Cells}

Since the usual initial point of infection by $S$. aureus is epithelial cells, colonization on the cell surface and their invasion through SrtA-mediated cell surface proteins may result in acute and chronic infection (Gómez et al., 2004). Therefore, the effect of Tax on the internalization of $S$. aureus into A549 cells was investigated. As demonstrated in Figure 3D, the number of bacteria entering cells was reduced significantly following treatment with $200 \mu \mathrm{M} \operatorname{Tax}(P<0.001)$, suggesting that 

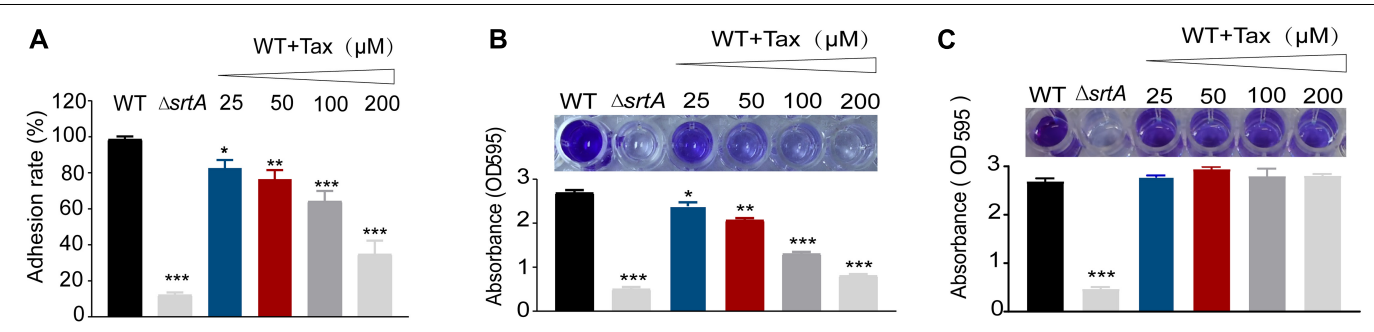

D

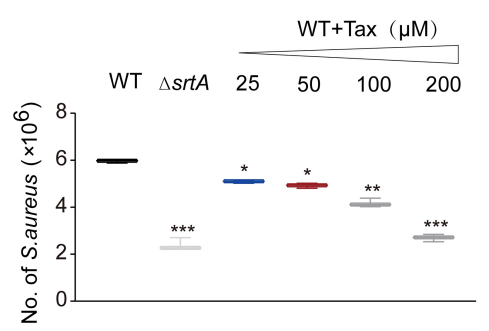

E

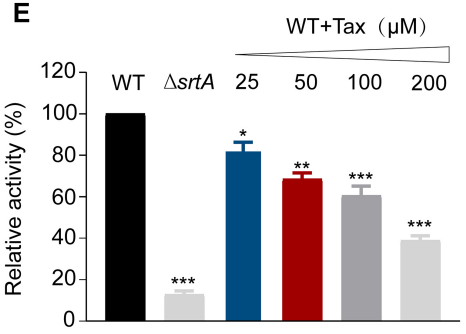

FIGURE 3 | Effect of SrtA inhibitor on virulence-related phenotypes in S. aureus Newman strain. (A) Impact of Tax on the ability of S. aureus to adhere to fibrinogen. (B) Biofilm formation of $S$. aureus in the presence of different concentrations of Tax. (C) Mature biofilms of $S$. aureus in the presence of different concentrations of Tax. The $\Delta$ sitA group represented the positive control. (D) Tax affects internalization of S. aureus into A549 cells. A549 cells were infected with S. aureus pretreated with different concentrations of Tax then lysed $2 \mathrm{~h}$ post-infection. The number of viable $S$. aureus in the cells was quantified by serial dilution on TSA agar plates. (E) Effects of Tax on S. aureus protein A (SpA) using FITC-labeled rabbit IgG. Error bars represent means \pm SD of three replicates. ${ }^{\star} P<0.05$, ${ }^{\star \star} P<0.01$, ${ }^{* \star *} P<0.001$ calculated with a two-tailed Student's $t$-test.

Tax suppresses the internalization of $S$. aureus by inhibition of SrtA, this may be because Tax reduces the anchoring of bacterial surface proteins required for internalization by inhibiting SrtA.

\section{Tax Influences Anchoring of SpA in \\ S. aureus}

In $S$. aureus, SrtA can anchor a variety of different surface proteins onto the bacterial envelope (Mazmanian et al., 2002; Falugi et al., 2013). Staphylococcal protein A (SpA) is able to specifically bind the FC $\gamma$ and Fab regions of IgG. Although there was strong evidence that Tax can inhibit SrtA in vitro, it was of great significance to further quantify the surface SpA after treatment with Tax. In the control group, $\Delta s r t A$ displayed weak fluorescence, indicating that it seemed to have completely lost the ability to anchor SpA to the cell wall. After treatment with $200 \mu \mathrm{M}$ Tax, S. aureus displayed a clear decrease in fluorescence, with a relative activity $36.12 \pm 1.59 \%$ that of the WT group $(p<0.001)$. These results suggests that Tax can reduce the amount of anchored SpA in the cell wall by inhibiting the activity of SrtA (Figure 3E).

\section{Tax Has No Apparent Influence on SrtA Expression in S. aureus}

Western blot analysis was used to further evaluate the effect of Tax on SrtA expression Compared with the untreated group, there was no apparent effect on SrtA expression, indicating that Tax effectively blocked the function of SrtA through a mechanism other than inhibition of its expression (Figure 4A).

\section{Determination of the Molecular Mechanism of the Interaction Between Tax and SrtA}

To explore the interaction between Tax and SrtA, an LSPR experiment was performed. The root mean square fluctuations (RMSF) suggested that SrtA exhibited different flexibility in binding sites with and without Tax (Figure 5A). The results revealed that Tax interacts directly with SrtA in a dose-dependent manner, with a $K_{\mathrm{D}}$ of $1.65 \times 10^{-4} \mathrm{~mol} / \mathrm{L}$ (Figure $4 \mathrm{~B}$ ). These data indicate that Tax binds directly to SrtA. To investigate the mechanism of the inhibition of SrtA by Tax in more depth, molecular modeling studies were performed. Through analysis of an in silico model of the SrtA-Tax complex, it was found that the Asp-170 residue provides a strong electrostatic $\left(\Delta E_{\text {ele }}\right)$ contribution, with $\Delta E_{\text {ele }}<-14.0 \mathrm{kcal} / \mathrm{mol}$ (Figure 5B). Asp-170 was found to have the ability to form a strong hydrogen bond with Tax, with a bond length of $2.0 \AA$ (Figure 5B). In addition, Gln-172 provided a significant van der Waals force contribution $\left(\Delta E_{\mathrm{vdw}}<-2.5 \mathrm{kcal} / \mathrm{mol}\right)$ (Figure 5B), due to the proximity of Gln-172 to Tax (Figure 5C). Except for Gln-172, the majority of energetic interactions for decomposition stemmed from van der Waals interactions, and mostly through the hydrophobic interactions of Val-166, Val168, Leu-169, and Val-201. Finally, the total binding free energy of the SrtA-Tax complex $\left(\Delta G_{\text {bind }}\right)$ was calculated, according to the MMGBSA method (Ylilauri and Pentikäinen, 2013), to be $-19.2 \mathrm{kcal} / \mathrm{mol}$, indicating that the complexation of Tax with SrtA is strong.

Molecular modeling studies highlight the benefits of performing site-directed mutagenesis studies. Therefore, 

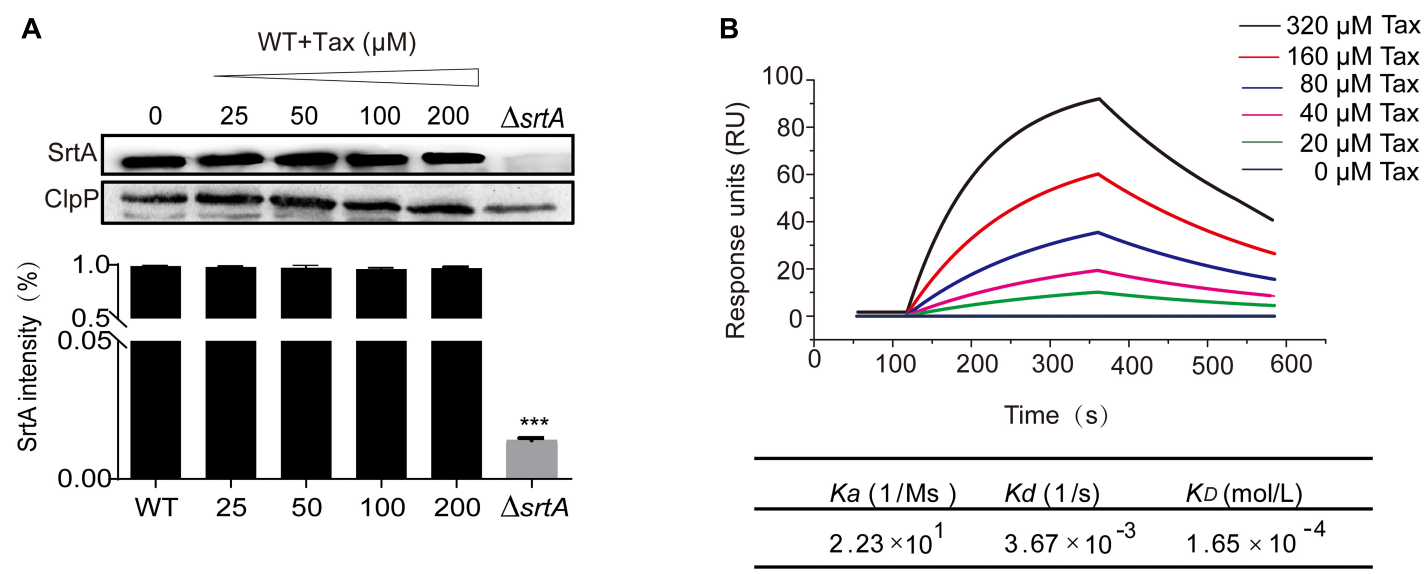

FIGURE 4 | Expression of SrtA in the presence of Tax and the interaction of different concentrations of Tax with SrtA. (A) Western blot analysis of SrtA protein from S. aureus treated with various concentrations of Tax and grayscale analysis of SitA protein bands. (B) LSPR analysis verified the binding affinity of Tax with SrtA. Error bars represent means $\pm S D$ of three replicates. ${ }^{\star \star \star} P<0.001$ calculated with a two-tailed Student's $t$-test.
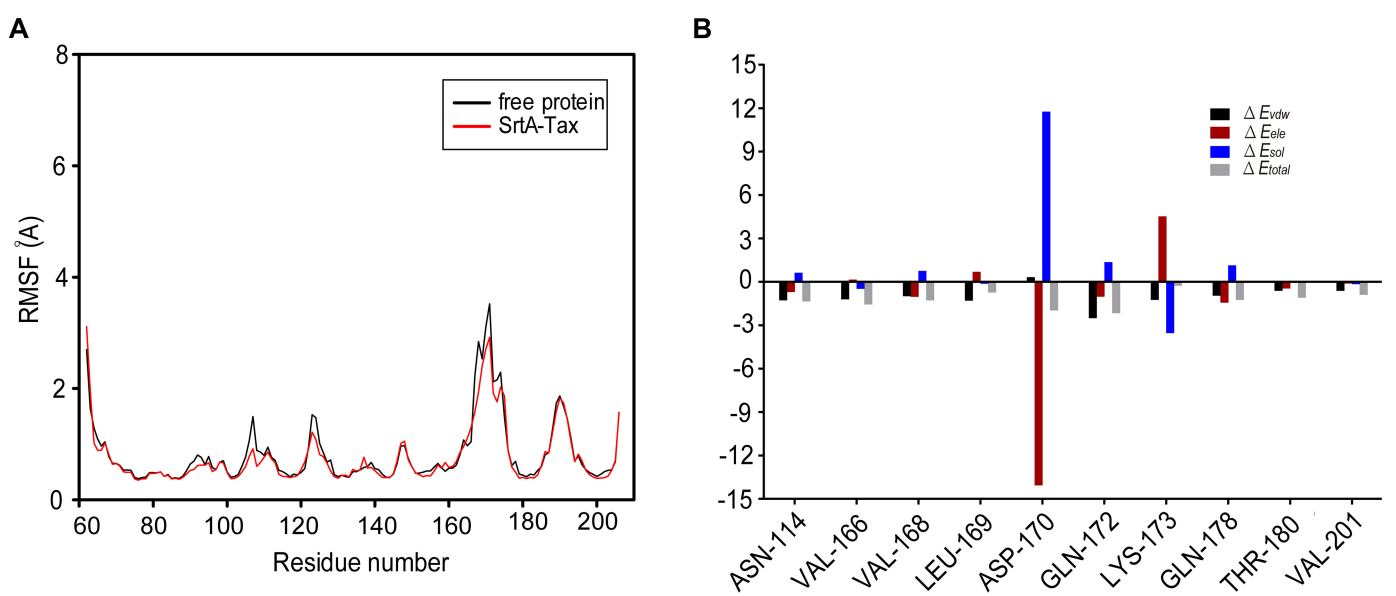

C

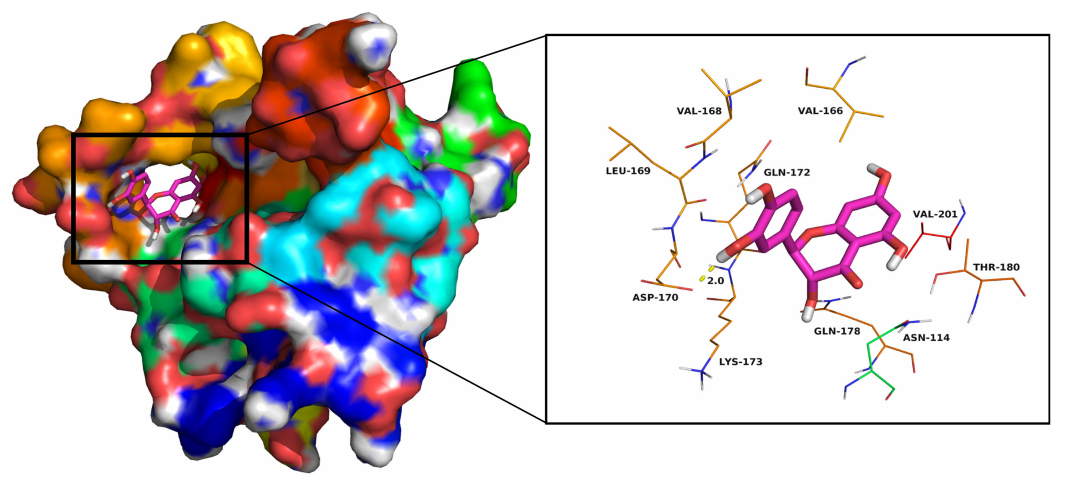

FIGURE 5 | Molecular modeling of the interaction between Tax and SrtA. (A) RMSF ( $\AA$ ) graph of free-SrtA (black) and the SrtA-Tax (red) complex during 40-ns MD. (B) Docking model of Tax with SrtA during a molecular dynamics simulation. (C) Binding free energy decomposition in each residue between Tax and modeled S. aureus SrtA.

fluorescence quenching experiments were utilized to determine the binding affinity of Tax with SrtA and SrtA mutants (D170A, Q172A). As displayed in Table 2, the binding constant $K_{\mathrm{A}}$ for
Tax with each SrtA mutant (D170A, Q172A) was significantly lower than that for WT SrtA, indicating that residues Asp-170 and Gln-172 were pivotal binding sites for Tax with SrtA. 
TABLE 2 | The values of the binding constants $\left(K_{A}\right)$ based on fluorescence quenching assay.

\begin{tabular}{lccc}
\hline Proteins & WT-SrtA & D170A & Q172A \\
\hline$K_{\mathrm{A}}\left(1 \times 10^{4}\right) \mathrm{l} / \mathrm{mol}$ & 6.4 & 2.69 & 3.85 \\
$\mathrm{n}$ & 0.9682 & 0.9341 & 0.8912 \\
\hline
\end{tabular}

Taken together, the results confirm that there is a direct interaction between Tax and SrtA with an inhibitory effect exerted via its direct binding with key residues of SrtA. Confirmation of this interaction allowed additional evaluation of the protective effect of Tax on S. aureus infection in vivo.

\section{Tax Protects Mice From MRSA-Induced Pneumonia}

Pneumonia caused by MRSA is clinically critical due to its complexity, the high incidence of complications, and high rates of mortality (Michalopoulos and Falagas, 2006). Therefore, the protective effects of Tax were evaluated in a murine model of MRSA-induced pneumonia.

Survival rate was examined by the intranasal administration of lethal doses of $S$. aureus USA300 to mice, with subsequent treatment with Tax every $12 \mathrm{~h}$. The mortality rate was recorded at $12 \mathrm{~h}$ intervals for $96 \mathrm{~h}$. As presented in Figure 6A, only 20\% of mice survived when challenged with S. aureus USA300 $96 \mathrm{~h}$

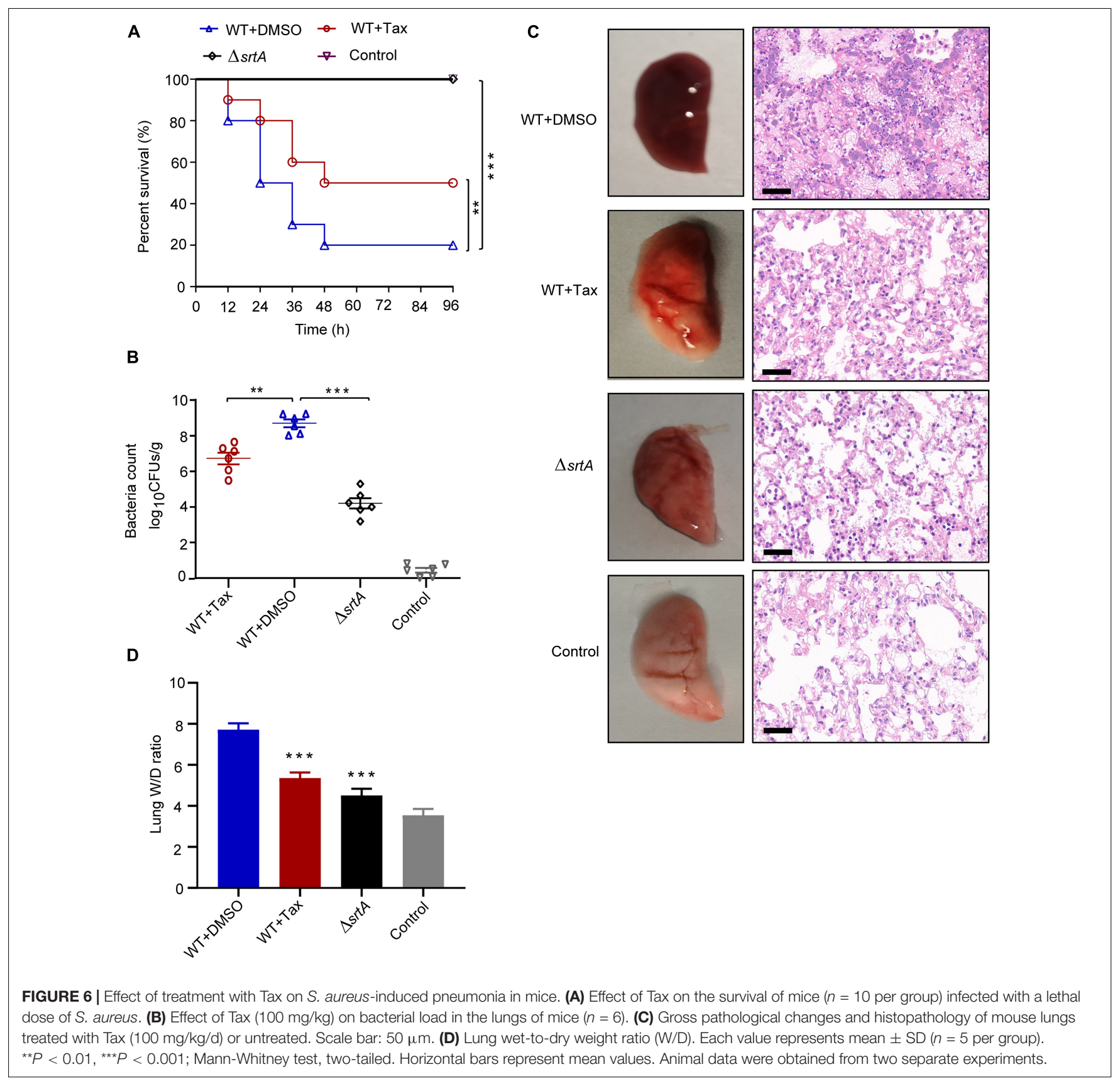


post-infection, while infection in the $\Delta s r t A$ group resulted in $100 \%$ survival. This indicates that SrtA is key to the pathogenesis of $S$. aureus pneumonia, consistent with previous reports (Cascioferro et al., 2014). Importantly, $100 \mathrm{mg} / \mathrm{kg}$ treatment of Tax significantly improved the survival rate of mice to $50 \%$ $(p<0.01)$, particularly during the early stages of infection. These findings revealed that Tax provided a strong protective effect against $S$. aureus infection in vivo.

The bacterial load in the lungs of the infected group was $8.56 \pm 1.34 \mathrm{lg}$ CFU/g (Figure 6B). After treatment with Tax, the bacterial load decreased to $6.73 \pm 0.69 \mathrm{lg} \mathrm{CFU} / \mathrm{g}$, demonstrating its significant inhibition of $S$. aureus invasion in the lungs.

The pathological changes in mouse lung tissue were further evaluated. Firstly, the appearance of the lung tissue in each group was analyzed. Soft and elastic lung tissue was observed in the control (uninfected) group, whereas lungs infected with S. aureus USA300 displayed significant hyperemia and low levels of elasticity, consistent with previous results. Following their treatment with Tax, the lung tissue of infected mice was only slightly red and the extent of congestion was significantly reduced, while elasticity was restored (Figure 6C, left). In addition, histopathological examination demonstrated that the lung tissue of the WT group ( $S$. aureus) was clearly hyperemic with a large number of inflammatory cells accumulated within the alveoli. However, treatment with Tax significantly reduced inflammation, as confirmed by the reduced accumulation of inflammatory cells within the alveolar spaces, and relatively complete alveolar structure (Figure 6C, right).

Furthermore, lung W/D ratios, recorded to evaluate the severity of lung injury (Xiao et al., 2008), increased from $3.53 \pm 0.16$ to $7.71 \pm 0.62$ after infection with $S$. aureus USA300 (Figure 6D). Conversely, the $\mathrm{W} / \mathrm{D}$ ratio decreased significantly to $5.35 \pm 0.34$ in mice treated with Tax $(100 \mathrm{mg} / \mathrm{kg})(P<0.001)$.
Taken together, we conclude that Tax attenuates the virulence of $S$. aureus in vivo and provides significant protection against lethal $S$. aureus-induced pneumonia. In addition, the acute toxicity test indicated that no signs of malaise, or tardy or inanimate behavior were observed following intraperitoneal injection of $200 \mathrm{mg} / \mathrm{kg}$ Tax.

\section{DISCUSSION}

The evolution, spread, and accumulation of multidrug-resistant (MDR) pathogens, such as MRSA represent a significant hidden risk to human public health (Skaar, 2010). Recent studies have shown that the proportion of MRSA isolated from patients is increasing, leading to significant incidence rate and mortality (Iwata et al., 2020). Antibiotics identified from other microorganisms have always been the primary weapon to combat bacterial infection (Rasko and Sperandio, 2010). These antibiotics rely on disrupting the key components in bacterial synthesis and assembly such as cell wall synthesis, DNA replication and protein synthesis (Mann, 2003). The effective bactericidal effect of these antibiotics also caused great survival pressure on the pathogens, making the rapid production of drug-resistant bacteria (Werner et al., 2008; Rasko and Sperandio, 2010). Therefore, it is imperative to develop alternatives to antibiotics which can not only inhibit infection but also avoid the production of drug-resistant bacteria. A promising strategy is to develop antivirulence therapies. The purpose of antivirulence strategies is not to kill pathogens directly, but to disarm them and prevent their attack on the host. This would not, therefore, exert selective pressure and so reduces the risk of drug resistance to a great extent (Hou et al., 2018). Moreover, a significant advantage of antivirulence strategies is that they reduce the damage to host

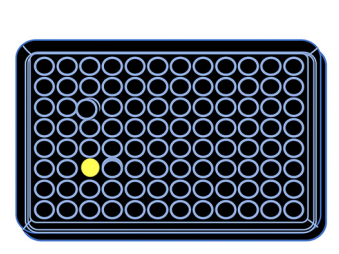

Compound library<smiles>O=c1c(O)c(-c2ccc(O)c(O)c2)oc2cc(O)cc(O)c12</smiles>
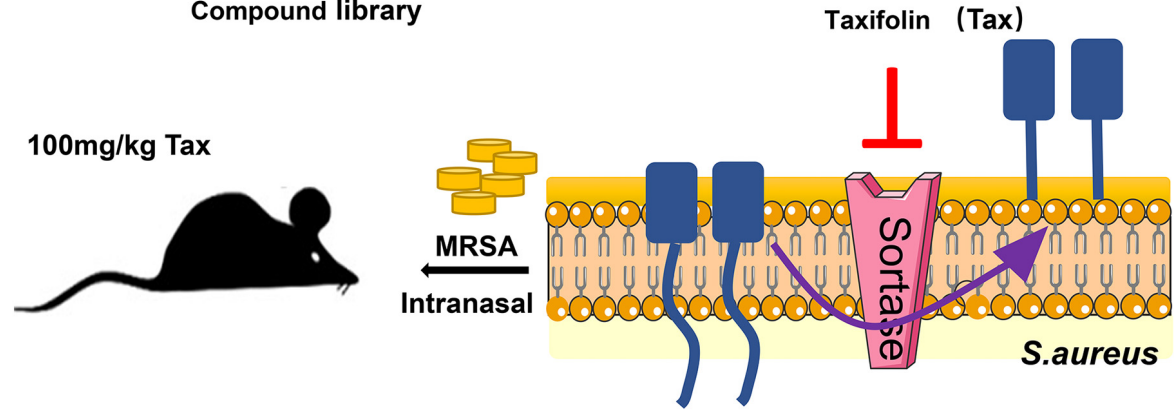

Anchoring of surface proteins, such as FnbA, FnbB, spa

FIGURE 7 | Experimental flow chart. 
microbiota, overcoming the adverse reactions and serious side effects of antibiotic therapies (Buroni and Chiarelli, 2020).

SrtA can recognize, cleave, and anchor specific LPXTGcontaining proteins which contribute to the bacterial infection process (Si et al., 2016), many of those surface proteins mediate bacterial colonization to host tissues and cells, the formation of biofilms and evasion of the immune response, etc. (Geoghegan and Foster, 2017). In addition, SrtA is constitutively expressed in all clinical isolates (Marraffini et al., 2006; Foster et al., 2014). Therefore, SrtA has long been recognized to be an important virulence factor of $S$. aureus and a promising pharmacological target of antivirulence strategies.

The experimental flow chart is shown in Figure 7. We identified the natural compound Tax that could block SrtA activity, with an $\mathrm{IC}_{50}$ of $24.53 \pm 0.42 \mu \mathrm{M}$. Inhibitors of SrtA can be categorized as either covalent or non-covalent (Jackson et al., 2017; Jaudzems et al., 2020). The formation of covalent bonds occurs via the reaction of an inhibitor with the cysteine active site (Hou et al., 2018; Barthels et al., 2020). We found that Tax is a non-covalent inhibitor that binds reversibly to SrtA. Reversible inhibitors might be a promising alternative, which overcome the drawbacks of the irreversible inhibitors, such as high toxicity, non-recoverability, non-repairability and other side effects (Beck et al., 2012). Importantly, Tax exhibited no cytotoxicity to mammalian cells (HEK293 and HepG2) at the concentration required to inhibit SrtA. This satisfies the main criteria for an ideal antibacterial agent: low selectivity pressure that avoids the generation of drug resistance (Schneewind and Missiakas, 2019). S. aureus is considered notorious due to its extraordinary capability to create a biofilm (Oliveira et al., 2018), a surface-attached encasement of cells and matrix. Biofilms lead to increased antibiotic resistance and evasion of the host immune system, increasing the complexity of the existing problem of antibiotic resistance (Vermote and Van Calenbergh, 2017; Graf et al., 2019). In the present study, our results showed that the coincubation of $S$. aureus with Tax led to decreased biofilm formation but did not affect the mature biofilm, which indicates that SrtA inhibited the formation of biofilm by inhibiting the anchoring of surface protein required in the adhesion stage of biofilm (Ming et al., 2017; Vazquez-Armenta et al., 2018). Moreover, the MD simulation and mutagenesis study indicated that Tax binds to the binding pocket of SrtA, depending mostly on hydrogen bonding, and electrostatic and van der Waals interactions, in which Asp-170 and Gln-172 play an important role.

Bacterial strains with a mutation of SrtA have exhibited attenuated virulence in a mouse infection model (Chen et al., 2005), suggesting that SrtA performs a critical role in staphylococcal pneumonia. Therefore, inhibition of surface

\section{REFERENCES}

Angelis, A., Hubert, J., Aligiannis, N., Michalea, R., Abedini, A., Nuzillard, J.M., et al. (2016). Bio-guided isolation of methanol-soluble metabolites of common spruce (Picea abies) bark by-products and investigation of their protein anchoring through the interference of SrtA should affect the ability of $S$. aureus to establish pulmonary infection. As expected, we observed that Tax significantly protected mice from challenge by lethal doses of $S$. aureus USA300, resulting in a reduction in bacterial burden in lung tissue. In addition, the safety of Tax was verified by acute toxicity testing which indicated that Tax has the potential for further development and clinical application.

Collectively, the present study reports on the discovery that the natural compound Tax is a specific SrtA inhibitor that is safe and efficacious, able to attenuate MRSA virulence in vitro and in vivo and the potential for development into a novel antivirulence agent. In addition, sortases possess an LPXTG sorting signal which is present in almost all strains of low G + C Gram-positive bacteria (Sillanpää et al., 2010; Spirig et al., 2011; van Harten et al., 2017; Kang et al., 2020). This suggests that SrtA inhibitors have the potential for further development and could be widely used in the treatment of multiple Grampositive infections.

\section{DATA AVAILABILITY STATEMENT}

The original contributions presented in the study are included in the article/supplementary material, further inquiries can be directed to the corresponding author/s.

\section{ETHICS STATEMENT}

The animal study was reviewed and approved by Institutional Animal Care and Use Committee (IACUC) of Jilin University.

\section{AUTHOR CONTRIBUTIONS}

QL, GW, and DW conceived and designed the experiments. LW, SJ, and SG performed and analyzed the experiments. LS, HQ, and KW performed the molecular dynamics simulation. LW prepared the original manuscript and revised the manuscript.

\section{FUNDING}

This work was supported by the Science Foundation of Jilin Province, China (No. 20180101276JC), the National Key Research and Development Program of China (No. 2018YFD0500300), the National Project of Infectious Disease (No. 2017ZX10304402003009), and the National Key Technology R\&D Program (No. 2016YFD0501307).

dermo-cosmetic properties. Molecules 21:1586. doi: 10.3390/molecules2111 1586

Barthels, F., Marincola, G., Marciniak, T., Konhäuser, M., Hammerschmidt, S., Bierlmeier, J., et al. (2020). Asymmetric Disulfanylbenzamides as Irreversible and Selective Inhibitors of Staphylococcus aureus 
Sortase A. ChemMedChem 15, 839-850. doi: $10.1002 / \mathrm{cmdc} .20190$ 0687

Beck, P., Dubiella, C., and Groll, M. (2012). Covalent and non-covalent reversible proteasome inhibition. Biol. Chem. 393, 1101-1120. doi: 10.1515/hsz-20120212

Buroni, S., and Chiarelli, L. R. (2020). Antivirulence compounds: a future direction to overcome antibiotic resistance? Fut. Microbiol. 15, 299-301. doi: 10.2217/ fmb-2019-0294

Carmichael, N. J. E. O. T. (2014). European Centre for Ecotoxicology and Toxicology of Chemicals. Brussels: ECETOC, 547-548.

Cascioferro, S., Totsika, M., and Schillaci, D. (2014). Sortase A: an ideal target for anti-virulence drug development. Microb. Pathog. 77, 105-112. doi: 10.1016/j. micpath.2014.10.007

Chan, A. H., Yi, S. W., Weiner, E. M., Amer, B. R., Sue, C. K., Wereszczynski, J., et al. (2017). NMR structure-based optimization of Staphylococcus aureus sortase A pyridazinone inhibitors. Chem. Biol. Drug Des. 90, 327-344. doi: 10.1111/cbdd. 12962

Chen, S., Paterson, G. K., Tong, H. H., Mitchell, T. J., and DeMaria, T. F. (2005). Sortase A contributes to pneumococcal nasopharyngeal colonization in the chinchilla model. FEMS Microbiol. Lett. 253, 151-154. doi: 10.1016/j.femsle. 2005.09.052

Cheng, A. G., Kim, H. K., Burts, M. L., Krausz, T., Schneewind, O., and Missiakas, D. M. (2009). Genetic requirements for Staphylococcus aureus abscess formation and persistence in host tissues. FASEB J. 23, 3393-3404. doi: 10.1096/fj.09-135467

Chenna, B. C., King, J. R., Shinkre, B. A., Glover, A. L., Lucius, A. L., and Velu, S. E. (2010). Synthesis and structure activity relationship studies of novel Staphylococcus aureus Sortase A inhibitors. Eur. J. Med. Chem. 45, 3752-3761. doi: 10.1016/j.ejmech.2010.05.024

Delgado-Valverde, M., Valiente-Mendez, A., Torres, E., Almirante, B., GómezZorrilla, S., Borrell, N., et al. (2017). MIC of amoxicillin/clavulanate according to CLSI and EUCAST: discrepancies and clinical impact in patients with bloodstream infections due to Enterobacteriaceae. J. Antimicrob. Chemother. 72, 1478-1487. doi: 10.1093/jac/dkw562

Falugi, F., Kim, H. K., Missiakas, D. M., and Schneewind, O. (2013). Role of protein $\mathrm{A}$ in the evasion of host adaptive immune responses by Staphylococcus aureus. mBio 4, e575-e513. doi: 10.1128/mBio.00575-13

Foster, T. J., Geoghegan, J. A., Ganesh, V. K., and Höök, M. (2014). Adhesion, invasion and evasion: the many functions of the surface proteins of Staphylococcus aureus. Nat. Rev. Microbiol. 12, 49-62. doi: 10.1038/ nrmicro3161

Galar, A., Weil, A. A., Dudzinski, D. M., Muñoz, P., and Siedner, M. J. (2019). Methicillin-Resistant Staphylococcus aureus Prosthetic Valve Endocarditis: Pathophysiology, Epidemiology, Clinical Presentation, Diagnosis, and Management. Clin. Microbiol. Rev. 32, 41-18. doi: 10.1128/cmr.00041-18

Geoghegan, J. A., and Foster, T. J. (2017). Cell Wall-Anchored Surface Proteins of Staphylococcus aureus: Many Proteins, Multiple Functions. Curr. Top Microbiol. Immunol. 409, 95-120. doi: 10.1007/82_2015_5002

Goetghebeur, M., Landry, P. A., Han, D., and Vicente, C. (2007). Methicillinresistant Staphylococcus aureus: A public health issue with economic consequences. Can. J. Infect. Dis. Med. Microbiol. 18, 27-34. doi: 10.1155/2007/ 253947

Gómez, M. I., Lee, A., Reddy, B., Muir, A., Soong, G., Pitt, A., et al. (2004). Staphylococcus aureus protein A induces airway epithelial inflammatory responses by activating TNFR1. Nat. Med. 10, 842-848. doi: 10.1038/ nm1079

Götz, A. W., Williamson, M. J., Xu, D., Poole, D., Le Grand, S., and Walker, R. C. (2012). Routine Microsecond Molecular Dynamics Simulations with AMBER on GPUs. 1. Generalized Born. J. Chem. Theory Comput. 8, 1542-1555. doi: $10.1021 /$ ct $200909 j$

Graf, A. C., Leonard, A., Schäuble, M., Rieckmann, L. M., Hoyer, J., Maass, S., et al. (2019). Virulence Factors Produced by Staphylococcus aureus Biofilms Have a Moonlighting Function Contributing to Biofilm Integrity. Mol. Cell Proteomics 18, 1036-1053. doi: 10.1074/mcp.RA118.001120

Hou, X., Wang, M., Wen, Y., Ni, T., Guan, X., Lan, L., et al. (2018). Quinone skeleton as a new class of irreversible inhibitors against Staphylococcus aureus sortase A. Bioorg. Med. Chem. Lett. 28, 1864-1869. doi: 10.1016/j.bmcl.2018.04. 005
Iwata, Y., Sakai, N., Yoneda, I., Satou, K., Furuichi, K., Senda, Y., et al. (2020). The increased frequency of methicillin-resistant Staphylococcus aureus with low MIC of beta-lactam antibiotics isolated from hospitalized patients. J. Infect. Chemother. 26, 604-610. doi: 10.1016/j.jiac.2020.01.016

Jackson, P. A., Widen, J. C., Harki, D. A., and Brummond, K. M. (2017). Covalent Modifiers: A Chemical Perspective on the Reactivity of $\alpha, \beta$-Unsaturated Carbonyls with Thiols via Hetero-Michael Addition Reactions. J. Med. Chem. 60, 839-885. doi: 10.1021/acs.jmedchem.6b00788

Jaudzems, K., Kurbatska, V., Je Kabsons, A., Bobrovs, R., Rudevica, Z., and Leonchiks, A. (2020). Targeting Bacterial Sortase A with Covalent Inhibitors: 27 New Starting Points for Structure-Based Hit-to-Lead Optimization. ACS Infect. Dis. 6, 186-194. doi: 10.1021/acsinfecdis.9b00265

Kali, A. (2015). Antibiotics and bioactive natural products in treatment of methicillin resistant Staphylococcus aureus: A brief review. Pharmacogn. Rev. 9, 29-34. doi: 10.4103/0973-7847.156329

Kang, C. Y., Huang, I. H., Chou, C. C., Wu, T. Y., Chang, J. C., Hsiao, Y. Y., et al. (2020). Functional analysis of Clostridium difficile sortase B reveals key residues for catalytic activity and substrate specificity. J. Biol. Chem. 295, 3734-3745. doi: 10.1074/jbc.RA119.011322

Kaur, I. (2016). Novel Strategies to Combat Antimicrobial Resistance. J. Infect. Dis. Therapy 4:1000292.

Kruger, R. G., Dostal, P., and McCafferty, D. G. (2002). An economical and preparative orthogonal solid phase synthesis of fluorescein and rhodamine derivatized peptides: FRET substrates for the Staphylococcus aureus sortase SrtA transpeptidase reaction. Chem. Commun. 2002, 2092-2093. doi: 10.1039/ b206303d

Lake, J. G., Weiner, L. M., Milstone, A. M., Saiman, L., Magill, S. S., and See, I. (2018). Pathogen Distribution and Antimicrobial Resistance Among Pediatric Healthcare-Associated Infections Reported to the National Healthcare Safety Network, 2011-2014. Infect. Control. Hosp. Epidemiol. 39, 1-11. doi: 10.1017/ ice.2017.236

Liu, Y., Li, R., Xiao, X., and Wang, Z. (2019). Antibiotic adjuvants: an alternative approach to overcome multi-drug resistant Gram-negative bacteria. Crit. Rev. Microbiol. 45, 301-314. doi: 10.1080/1040841x.2019.1599813

Mandal, S. M., Roy, A., Ghosh, A. K., Hazra, T. K., Basak, A., and Franco, O. L. (2014). Challenges and future prospects of antibiotic therapy: from peptides to phages utilization. Front. Pharmacol. 5:105. doi: 10.3389/fphar.2014.00105

Mann, J. (2003). Antibiotics : actions, origins, resistance. Washington, DC: ASM Press.

Maresso, A. W., Wu, R., Kern, J. W., Zhang, R., Janik, D., Missiakas, D. M., et al. (2007). Activation of inhibitors by sortase triggers irreversible modification of the active site. J. Biol. Chem. 282, 23129-23139. doi: 10.1074/jbc.M7018 57200

Marraffini, L. A., Dedent, A. C., and Schneewind, O. (2006). Sortases and the art of anchoring proteins to the envelopes of gram-positive bacteria. Microbiol. Mol. Biol. Rev. 70, 192-221. doi: 10.1128/mmbr.70.1.192-221.2006

Mazmanian, S. K., Liu, G., Jensen, E. R., Lenoy, E., and Schneewind, O. (2000). Staphylococcus aureus sortase mutants defective in the display of surface proteins and in the pathogenesis of animal infections. Proc. Natl. Acad. Sci. US A. 97, 5510-5515. doi: 10.1073/pnas.080520697

Mazmanian, S. K., Ton-That, H., Su, K., and Schneewind, O. (2002). An ironregulated sortase anchors a class of surface protein during Staphylococcus aureus pathogenesis. Proc. Natl. Acad. Sci. U S A. 99, 2293-2298. doi: 10.1073/pnas. 032523999

Michalopoulos, A., and Falagas, M. E. (2006). Multi-systemic methicillin resistant Staphylococcus aureus (MRSA) community-acquired infection. Med. Sci. Monit. 12, Cs39-Cs43.

Ming, D., Wang, D., Cao, F., Xiang, H., Mu, D., Cao, J., et al. (2017). Kaempferol Inhibits the Primary Attachment Phase of Biofilm Formation in Staphylococcus aureus. Front. Microbiol. 8:2263. doi: 10.3389/fmicb.2017.02263

Nisar, P., Ali, N., Rahman, L., Ali, M., and Shinwari, Z. K. (2019). Antimicrobial activities of biologically synthesized metal nanoparticles: an insight into the mechanism of action. J. Biol. Inorg. Chem. 24, 929-941. doi: 10.1007/s00775019-01717-7

Niu, X., Gao, Y., Yu, Y., Yang, Y., Wang, G., Sun, L., et al. (2019). Molecular Modelling reveals the inhibition mechanism and structure-activity relationship of curcumin and its analogues to Staphylococcal aureus Sortase A. J. Biomol. Struct. Dyn. 37, 1220-1230. doi: 10.1080/07391102.2018.1453380 
Oh, K. B., Kim, S. H., Lee, J., Cho, W. J., Lee, T., and Kim, S. (2004). Discovery of diarylacrylonitriles as a novel series of small molecule sortase A inhibitors. J. Med. Chem. 47, 2418-2421. doi: 10.1021/jm0498708

Oliveira, D., Borges, A., and Simões, M. (2018). Staphylococcus aureus Toxins and Their Molecular Activity in Infectious Diseases. Toxins 10:toxins10060252. doi: 10.3390/toxins10060252

Otto, M. (2018). Staphylococcal Biofilms. Microbiol. Spectr. 6:2018. doi: 10.1128/ microbiolspec.GPP3-0023-2018

Panneer Selvam, S., Roth, B. M., Nganga, R., Kim, J., Cooley, M. A., Helke, K., et al. (2018). Balance between senescence and apoptosis is regulated by telomere damage-induced association between p16 and caspase-3. J. Biol. Chem. 293, 9784-9800. doi: 10.1074/jbc.RA118.003506

Paterson, G. K., and Mitchell, T. J. (2004). The biology of Gram-positive sortase enzymes. Trends Microbiol. 12, 89-95. doi: 10.1016/j.tim.2003.12.007

Prestinaci, F., Pezzotti, P., and Pantosti, A. (2015). Antimicrobial resistance: a global multifaceted phenomenon. Pathog. Glob. Health 109, 309-318. doi: 10. 1179/2047773215y.0000000030

Rasko, D. A., and Sperandio, V. (2010). Anti-virulence strategies to combat bacteria-mediated disease. Nat. Rev. Drug. Discov. 9, 117-128. doi: 10.1038/ nrd3013

Razak, S., Afsar, T., Ullah, A., Almajwal, A., Alkholief, M., Alshamsan, A., et al. (2018). Taxifolin, a natural flavonoid interacts with cell cycle regulators causes cell cycle arrest and causes tumor regression by activating Wnt/ $\beta$-catenin signaling pathway. BMC Cancer 18:1043. doi: 10.1186/s12885-018-4959-4

Ren, L., Guo, H. N., Yang, J., Guo, X. Y., Wei, Y. S., and Yang, Z. (2020). Dissecting Efficacy and Metabolic Characteristic Mechanism of Taxifolin on Renal Fibrosis by Multivariate Approach and Ultra-Performance Liquid Chromatography Coupled With Mass Spectrometry-Based Metabolomics Strategy. Front. Pharmacol. 11:608511. doi: 10.3389/fphar.2020.608511

Sader, H. S., Flamm, R. K., and Jones, R. N. (2013). Antimicrobial activity of daptomycin tested against Gram-positive pathogens collected in Europe, Latin America, and selected countries in the Asia-Pacific Region (2011). Diagn. Microbiol. Infect. Dis. 75, 417-422. doi: 10.1016/j.diagmicrobio.2013.01.001

Schneewind, O., and Missiakas, D. (2019). Sortases, Surface Proteins, and Their Roles in Staphylococcus aureus Disease and Vaccine Development. Microbiol. Spectr. 7:2018. doi: 10.1128/microbiolspec.PSIB-0004-2018

Si, L., Li, P., Liu, X., and Luo, L. (2016). Chinese herb medicine against Sortase A catalyzed transformations, a key role in gram-positive bacterial infection progress. J. Enzyme Inhib. Med. Chem. 31, 184-196. doi: 10.1080/14756366. 2016.1178639

Sillanpää, J., Nallapareddy, S. R., Singh, K. V., Prakash, V. P., Fothergill, T., TonThat, H., et al. (2010). Characterization of the ebp(fm) pilus-encoding operon of Enterococcus faecium and its role in biofilm formation and virulence in a murine model of urinary tract infection. Virulence 1, 236-246. doi: 10.4161/ viru.1.4.11966

Skaar, E. P. (2010). The battle for iron between bacterial pathogens and their vertebrate hosts. PLoS Pathog. 6:e1000949. doi: 10.1371/journal.ppat.1000949

Smeltzer, M. S. (2016). Staphylococcus aureus Pathogenesis: The Importance of Reduced Cytotoxicity. Trends Microbiol. 24, 681-682. doi: 10.1016/j.tim.2016. 07.003

Song, T., Yang, Y., Wei, H., Xie, X., Lu, J., Zeng, Q., et al. (2019). Zfp217 mediates m6A mRNA methylation to orchestrate transcriptional and posttranscriptional regulation to promote adipogenic differentiation. Nucleic Acids Res. 47, 6130-6144. doi: 10.1093/nar/gkz312

Spirig, T., Weiner, E. M., and Clubb, R. T. (2011). Sortase enzymes in Grampositive bacteria. Mol. Microbiol. 82, 1044-1059. doi: 10.1111/j.1365-2958.2011. 07887.x

Suree, N., Jung, M. E., and Clubb, R. T. (2007). Recent advances towards new antiinfective agents that inhibit cell surface protein anchoring in Staphylococcus aureus and other gram-positive pathogens. Mini Rev. Med. Chem. 7, 991-1000. doi: 10.2174/138955707782110097

Tong, S. Y., Davis, J. S., Eichenberger, E., Holland, T. L., and Fowler, V. G. Jr. (2015). Staphylococcus aureus infections: epidemiology, pathophysiology, clinical manifestations, and management. Clin. Microbiol. Rev. 28, 603-661. doi: $10.1128 / \mathrm{cmr} .00134-14$

Trott, O., and Olson, A. J. (2010). AutoDock Vina: improving the speed and accuracy of docking with a new scoring function, efficient optimization, and multithreading. J. Comput. Chem. 31, 455-461. doi: 10.1002/jcc. 21334

van Harten, R. M., Willems, R. J. L., Martin, N. I., and Hendrickx, A. P. A. (2017). Multidrug-Resistant Enterococcal Infections: New Compounds, Novel Antimicrobial Therapies? Trends Microbiol. 25, 467-479. doi: 10.1016/j.tim. 2017.01.004

Vandenesch, F., Lina, G., and Henry, T. (2012). Staphylococcus aureus hemolysins, bi-component leukocidins, and cytolytic peptides: a redundant arsenal of membrane-damaging virulence factors? Front. Cell Infect. Microbiol. 2:12. doi: $10.3389 /$ fcimb.2012.00012

Vazquez-Armenta, F. J., Bernal-Mercado, A. T., Tapia-Rodriguez, M. R., GonzalezAguilar, G. A., Lopez-Zavala, A. A., Martinez-Tellez, M. A., et al. (2018). Quercetin reduces adhesion and inhibits biofilm development by Listeria monocytogenes by reducing the amount of extracellular proteins. Food Control 90, 266-273. doi: 10.1016/j.foodcont.2018.02.041

Vermote, A., and Van Calenbergh, S. (2017). Small-Molecule Potentiators for Conventional Antibiotics against Staphylococcus aureus. ACS Infect. Dis. 3, 780-796. doi: 10.1021/acsinfecdis.7b00084

Werner, G., Strommenger, B., and Witte, W. (2008). Acquired vancomycin resistance in clinically relevant pathogens. Fut. Microbiol. 3, 547-562. doi: 10. 2217/17460913.3.5.547

Wu, S. C., Liu, F., Zhu, K., and Shen, J. Z. (2019). Natural Products That Target Virulence Factors in Antibiotic-Resistant Staphylococcus aureus. J. Agric. Food Chem. 67, 13195-13211. doi: 10.1021/acs.jafc.9b05595

Xia, F., Li, X., Wang, B., Gong, P., Xiao, F., Yang, M., et al. (2016). Combination Therapy of LysGH15 and Apigenin as a New Strategy for Treating Pneumonia Caused by Staphylococcus aureus. Appl. Environ. Microbiol. 82, 87-94. doi: 10.1128/aem.02581-15

Xiao, G. L., Luo, Z. Q., Xiao, G., Li, C., Xiong, X. D., Yang, Y., et al. (2008). [Highdensity lipoprotein attenuates lipopolysaccharide-induced acute lung injury in mice]. Sheng Li Xue Bao 60, 403-408.

Xiao, Z., Liu, L., Tao, W., Pei, X., Wang, G., and Wang, M. (2018). Clostridium Tyrobutyricum Protect Intestinal Barrier Function from LPS-Induced Apoptosis via P38/JNK Signaling Pathway in IPECJ2 Cells. Cell Physiol. Biochem. 46, 1779-1792. doi: 10.1159/0004 89364

Yang, R., Zhang, C., and Su, Z. (2011). LSPR: an integrated periodicity detection algorithm for unevenly sampled temporal microarray data. Bioinformatics 27, 1023-1025. doi: 10.1093/bioinformatics/btr041

Ylilauri, M., and Pentikäinen, O. T. (2013). MMGBSA as a tool to understand the binding affinities of filamin-peptide interactions. J. Chem. Inf. Model 53, 2626-2633. doi: 10.1021/ci4002475

Zhulenkovs, D., Rudevica, Z., Jaudzems, K., Turks, M., and Leonchiks, A. (2014). Discovery and structure-activity relationship studies of irreversible benzisothiazolinone-based inhibitors against Staphylococcus aureus sortase A transpeptidase. Bioorg. Med. Chem. 22, 5988-6003. doi: 10.1016/j.bmc.2014.09. 011

Conflict of Interest: The authors declare that the research was conducted in the absence of any commercial or financial relationships that could be construed as a potential conflict of interest.

Copyright (c) 2021 Wang, Wang, Qu, Wang, Jing, Guan, Su, Li and Wang. This is an open-access article distributed under the terms of the Creative Commons Attribution License (CC BY). The use, distribution or reproduction in other forums is permitted, provided the original author(s) and the copyright owner(s) are credited and that the original publication in this journal is cited, in accordance with accepted academic practice. No use, distribution or reproduction is permitted which does not comply with these terms. 